\title{
How Distorted Thinking Influence Arab Children Academic Achievement in Israel?
}

\author{
Emad Gith
}

Correspondence: Emad Gith, PhD, Sakhnin Academic College for Teacher Education, Sakhnin 20173, Israel; Educational Psychological Services in Arraba Village, Israel; Department of Psychology, Ethics, and Law, International Center for Health, Law, and Ethics, Faculty of Law at the University of Haifa, Haifa, Israel.

\author{
Received: February 1, $2018 \quad$ Accepted: February 15, $2018 \quad$ Online Published: February 17, 2018 \\ doi:10.11114/jets.v6i3.3037～URL: https://doi.org/10.11114/jets.v6i3.3037
}

\begin{abstract}
The purpose of the current study was to examine the relation between the parents Cognitive Distortion and Arab children academic achievements in Israel. 52 fifth grade Arab Children and their parents from Israel were participated. The results indicated that parent's cognitive distortion related negatively to children academic achievements; there is a negative correlation between father's Cognitive distortion and children academic achievements and between mother's Cognitive distortion and children academic achievements. The current research concluded that Parent's Cognitive distortion has a greater relationship with children academic performance. The researchers recommend that appropriate measures, including cognitive mutual counseling program (parents and Children) should be put in place for the Children to achieve both their short-term and long-term educational goals.
\end{abstract}

Keywords: distorted thinking, Arab children, academic achievement

\section{Introduction}

Distorted thinking is related in the literature as negative biased information processing (Beck, 1985). It refers to reasoning process (negative thoughts) which distorts reality and affect an individual's perception of reality, in other words, they are simply ways that an individual's mind convinces him of something that is untrue, they also reinforce negative thinking or emotions, therefore, they convince them by giving rational explanation to the specific situation (McGrath \& Repetti, 2002). There is various distorted thinking which affect people views: Binocular vision, taking the negative details and magnify them filtering the positive aspects from the situation. Polarized thinking, it means treating with situations only in two ways: black or white, good or bad. Dark glasses, when picking on negative thought and the whole view will be dark and negative. Labeling and mislabeling, it is when attaching negative label to the individual. Should or must thinking, picking on what should or what must be done rather than thinking if we behaved well. Catastrophizing, it is when the individual expects a disaster. Control fallacies, the individual sees himself as controlled but helpless. Moreover, overgeneralizing, personalizing and jump to conclusion McGrath \& Repetti, 2002).

Factors correlating with academic performance of adolescents should be interesting area of investigation (Bahrami and Bahrami, 2015). Evidence has shown how such thinking distortions are related to academic achievement. Nasir, et al (2011) indicated that the rate of cognitive distortion is being increasing among children. In this case, Nevid and Rathus (2005), Children with distorted thinking tend to see the world through darkened mental filter, it affects their interpreting their life experiences, it may influence negatively their performance in academic activities because of their incorrect beliefs, they also exhibit negative thinking and disappointment when getting non-sufficient grade on a test, they expect the worst, focus on it (Ghaderi \& Salehi, 2011).

More essential factor is Parents Cognitive or thinking distortion who has an important effect of the Children academic achievements. In this vein, cognitive distortion excuse parents in restricting their children autonomy in the hope of minimizing the damaged outcomes. The mother who distorts her daughter "and minimize her improved achievements in hope for studying harder, will restrict her girl. Bader (2001) indicated that there is a relation between Parents cognitive distortion and children achievement, it means that Parents cognitive distortion influence negatively their children academic achievements.

Thus, the present study therefore focuses on parent's cognitive distortion as related factor of children academic performance. To this end, the current study the hypothesis: cognitive distortion is related significantly to children academic performance and particularly among Arab children in Israel. 
In order to understand the Arab society, the cognitive distortion of the parents, distortion gap between the Arab parents and modern Children, the current section will deal with Arab society properties.

\subsection{Arab Society in Israel: Parent's Background}

In recent years, Arab society in Israel has undergone significant changes in various aspects of life, such as social, economic, and educational changes. These include changes in the status of changes in the family structure, and socio-cultural transitions. Understanding these changes and their impact on Arab society in Israel in general and on the individuals, that constitute it in particular is a fascinating and important area of theoretical research (Dwairy, 2008).

Nearly 1.5 million Arab Israelis currently live in Israel, making up approximately $20 \%$ of the Israeli population. About 700,000 of the Arab population are Muslims, constituting 85\% of the non-Jewish citizens of Israel; 150,000 are Christian Arabs, and the rest are Druze, Circassians, and others. The Arab population in Israel lives in approximately 125 localities, of which two thirds are urban and the rest are rural. Most Arab villages and cities (79 in total) are located in northern Israel, particularly in the Jezereel Valley and near Acre. About 50\% of the population of northern Israel is Arab. Haifa and its vicinity are home to the second-largest Arab population in Israel; they include 23 localities, which make up 16\% of the entire Arab population (Dwairy, 2008).

Arab society places the highest value on harmony between humans and their surroundings (Zureik, 1979). It believes in the importance of maintaining family bonds and collective tendencies over individualist orientations and conduct (Dwairy, 2008). Religious and spiritual orientations often serve to maintain harmony between Arab society and its surroundings. Family relationships based on values of respect to adults, family relationship conservation, and the collective in the center (Abu-Baker \& Dwairy, 2003). In addition, emotional struggles and personal and interpersonal conflicts are often considered sinful or caused by the failure to obey the word of God and by ignoring his expectations (Dermalkonian, 1993; Haj Yahia, 1985). Arab society ultimately strives to live a successful, spiritual life while maintaining harmony with its surroundings and with nature.

Arabs in Israel live simultaneously in two different worlds. They are exposed to the Western culture of the country in which they live while maintaining their Eastern-style culture. Whereas the Israeli majority generally represents a modern, Western-oriented society, Arab culture in Israel still represents a traditional society (Dwairy, 2008).

This clash between two entirely different cultures leads to intercultural conflicts between two extremes (Gith, 2014a). Young, educated members of Arab society are the most inclined to struggles within the family as a result of the multicultural contexts in which they live. Living in both cultures in parallel may result in cultural conflicts between parents and their children, particularly among those who have received higher education. These cultural conflicts may affect the parents' influence on various aspects of their children's lives, such as selecting a spouse and the woman's ability to choose to pursue a career or stay at home (Al-Krenawi \& Lev-Wiesel, 1999).

Family struggles develop when the family or the family members do not maintain balance and harmony in their own lives, with their surroundings, and with the outside world. Young Arab adults who attend Israeli or Western universities and develop a Western, post-industrial, social perspective that focuses on the human ability to control nature and that views all problems as solvable may develop conflicts with the values of the Arab family in which they live, on both the personal and interpersonal levels (Haj Yahia, 1994).

Despite the transformations that Arab society is undergoing, powerful tendencies still exist toward a more collective orientation on the social and family levels, as opposed to an individualist orientation (Kulik, 2004). In Arab society, the needs of the family will always be given precedence over social relationships and friendships outside of the family. The Arab individual is raised to serve the family, meaning the collective (Dwairy, 2006); hence, the failure or success of the individual reflects on the family (Iancu et al., 2011).

The collectivism and traditional conceptions influence Arab children, who are influence by the parent's cognitive distortions while they face the modernity. Therefore, the current research will focus on the relation between parents' cognitive distortions and academic achievements of Arab Children in Israel.

\subsection{Aim of the Present Study}

The present study aimed to extend the existing literature by examining whether and how the Arab children academic achievement affected by parents' cognitive distortions in Israel.

\section{Method}

\subsection{Participating Students and Institutions}

Data was collected from 52 fifth grade Arab Children (and their parents) in two secondary schools located in north Israel of whom 30 were male and 22 females. The mean age was 10.1 years $(\mathrm{SD}=.39)$. Students were following. 


\subsection{Instrumentation}

Thinking distortions were measured using the Children's Negative Cognitive Error Questionnaire (CNCEQ; Leitenberg et al., 1986). The questionnaire contained 24-items, it provides scales scores of: catastrophizing, overgeneralization, personalizing and selective abstraction. Every subscale contains six scenarios (two social, two academic and two athletic) and a possible negative interpretation. The parent has to respond from 1(Not at all like I would think) to 5 (Almost exactly like I would think) how the items indicate his/her tendency toward thinking distortions.

In the vein of internal reliability of the questionnaire, it was reported in Leitenberg et al. (1986) and has this measure been used in subsequent research with children (e.g. Weems et al., 2001).

Academic Performance Scale (APS): academic achievement data of the Children were collected from teachers. This is a scale showing summary of the average grade points of the students. It was used to determine the academic performance of the child for the past two terms, the teacher has to describe child achievements from 1 (fail) to 6 (excellence). It contains 19 statements: 12 negative and 7 positive, describing children academic performance. The APS has a Cronbach alpha reliability coefficient of 0.92 .

\subsection{Design and Procedure}

Data was collected from two schools: Self-report parents' questionnaire measures of thinking distortions and academic achievements. Schools helped the researcher to recruit the appropriate parents for the current research. Permission to collect data was granted at an individual consent sought from parents and schools at the point of data collection.

The aims of the research along with anonymity and consent issues (including retrospective withdrawal) were explained to parents. Moreover, researchers answered questions about questionnaire items.

The current study used a correlation survey design. Data analysis was completed using Pearson analysis to test the hypotheses.

\section{Results}

The results show that parents' cognitive distortion significantly related negatively to children academic achievements $(\mathrm{r}=0.62, \mathrm{p}<0.05)$. There is a negative correlation between father's Cognitive distortion and children academic achievements $(r=-0.3, p<0.05)$ and between mother's Cognitive distortion and children academic achievements $(r=$ $-0.71, \mathrm{p}<0.05)$. Negative significant correlation found between polarized cognitive distortion and children academic achievements $(\mathrm{r}=-0.5, \mathrm{p}<0.05)$. negative significant correlation found between personalizing and children academic achievements $(r=-0.42, p<0.05)$, similarly, between jump to conclusion and children academic achievements $(r=-0.53$, $\mathrm{p}<0.05)$ and children academic achievements in order to deep in the results, the difference between fathers and mothers in Cognitive Distortion was examined. Table 1 shows this difference.

Table 1. The difference between fathers and mothers in cognitive distortion

\begin{tabular}{lllll}
\hline & M & SD & T & sig \\
Fathers & 3.1 & 0.9 & 1.34 & 0.02 \\
Mothers & 4.2 & 0.82 & & \\
\hline
\end{tabular}

The results in Table 2 show that mother cognitive distortion significantly higher $(\mathrm{M}=4.2, \mathrm{SD}=0.82)$ father $(\mathrm{M}=3.1$, $\mathrm{SD}=0.9)[\mathrm{t}(50)=1.34, \mathrm{p}<0.05]$.

\section{Discussion}

The purpose of the current study was to examine the relation between the parents Cognitive Distortion and Arab children academic achievements in Israel. The results indicated that parent's cognitive distortion related negatively to children academic achievements; there is a negative correlation between father's Cognitive distortion and children academic achievements and between mother's Cognitive distortion and children academic achievements. This finding is in line with McGrath and Repetti (2002) results that cognitive distortion is associated with academic performance.

The findings further imply Arab parents in traditional society have not learnt how to improve their interaction to their Children who are exposed to modern society due to their negative beliefs; they influence negatively on their children academic achievements and restrict them. It seems that those parents' beliefs are putting children at high risk of academic failures.

Overall, the findings of this study support other researchers: Nevid \& Rathus (2005); Nasir, et al., (2011); Ghaderi \& Salehi (2011) results. If this cognitive distortion is still addressed among Arab parents, the educational achievements of the Children are at stake. Therefore, the researchers recommend that appropriate measures, including cognitive mutual counseling program (parents and Children) should be put in place for the Children to achieve both their short-term and long-term educational goals.

\section{Limitations}

Considering the weakness of correlation in the current research, it may be argued that that the relationships among the variables investigated actually imply causal relationships between the variables. So, future research is required with 
more casual examination.

\section{Conclusion}

Parent's Cognitive distortion has a greater relationship with children academic performance. To these end, future researchers should focus on the connections between children negative beliefs and academic performance, father-mother Cognitive distortion difference and its influence on children academic performance.

\section{References}

Abu-Baker, K., \& Dwairy, M. (2003). Cultural norms versus state law in treating incest: A suggested model for Arab families. Child Abuse and Neglect, 27, 109-123. https://doi.org/10.1016/S0145-2134(02)00505-7

Al-Krenawi, A., \& Lev-Wiesel, R. (1999). Attitude towards marriage and marital quality: A comparison among Israeli Arabs differentiated by religion. Family Relations, 48, 51-56. https://doi.org/10.2307/585682

Bader, F. M. (2001). Parental acceptance-rejection and its relation with self-concept and its influence (impact) on the scholastic achievement in a sample of primary school Parental Acceptance and Rejection in the Arab World 31 female students in Jaddah City. Resilat el-Khalif al-Arabi (Saudi Arabia), 81, 53-76 (in Arabic).

Bahrami, D., \& Bahrami, M. A. (2015). The Relationship of Self-Esteem and Achievement Goals with Academic Performance. African Journal of Basic \& Applied Sciences, 7(1), 65-72.

Beck, A. T. (1985). Theoretical perspectives on clinical anxiety. In Anxiety and the anxiety disorders, Edited by: Tuma, A.H. and Maser, J.D. 183-198. Hillsdale, NJ: Erlbaum.

Dermalkonian, S. (1993). How rural and urban Arab families cope with mental disease before first hospitalization (Unpublished master's thesis). Hebrew University, Jerusalem, Israel.

Dwairy, M. (2008). Counseling Arab and Muslim clients. In Pedersen, P., Draguns, J. G., Lonner, W. J., and Trimble, J. E. (Eds.), Counseling Across Cultures. $6^{\text {th }}$ ed. Ch. 9 p. 147-160. https://doi.org/10.4135/9781483329314.n9

Ghaderi, A. R., \& Salehi, M. (2011). Anxiety Between Accounting and Management Students: Iranian Evidence. World Applied Sciences Journal, 12(8), 1299-1306.

Gith, E. (2014a). Adaptation in Shari'a law, its impact on the Muslim minority in Israel, and the therapist-patient relationship when psychological intervention is necessary. Health Law, 33, 21-34.

Haj, Y. M. (1985). Traditionalism and modernism in Arab society - Orientations regarding the mentally ill: The tendency to employ the mentally ill (Unpublished master's thesis). Hebrew University, Jerusalem, Israel.

Haj, Y. M. (1994). The Arab family in Israel: Cultural values and its connection to social work. Society and Welfare, 14, $12-13$.

Kulik, L. (2004). Strategies for managing home-work conflict and psychological well-being among Jews and Arabs in Israel: The impact of sex and sociocultural context. Families in Society, 85, 139-147. https://doi.org/10.1606/1044-3894.238

Leitenberg, H., Yost, L. W., \& Carroll-Wilson, M. (1986). Negative cognitive errors in children: Questionnaire development, normative data, and comparisons between children with and without self-reported symptoms of depression, low self-esteem, and evaluation anxiety. Journal of Consulting and Clinical Psychology, 54, 528-536. https://doi.org/10.1037/0022-006X.54.4.528

McGrath, E. P., \& Repetti, R. L. (2002). A longitudinal study of children's depressive symptoms, self perceptions, and cognitive distortions about the self. Journal of Abnormal Psychology, 111(1), 77-87. Washington, DC: American Psychological Association, Inc.. https://doi.org/10.1037/0021-843X.111.1.77

Nasir, R., Zainah, A. Z., Khairudin, R., Ismail, R., Yusooff, F., \& Lukman, Z. M. (2011). Psychological factors of self-esteem and cognitive distortion in prostitution. World Applied Sciences Journal, 12, 35-39.

Nevid, J. S., \& Rathus, S. A. (2005). Psychology and the challenges of life. United State America, John Wiley \& Sons, INC.

Weems, C. F., Berman, S. L., Silverman, W. K., \& Saavedra, L. M. (2001). Cognitive errors in youth with anxiety disorders: The linkages between negative cognitive errors and anxious symptoms. Cognitive Therapy and Research, 25, 559575. https://doi.org/10.1023/A:1005505531527

Zureik, E. T. (1979). The Palestinians in Israel: A Study in Internal Colonialism, London: Routledge and Keagan Paul.

\section{Copyrights}

Copyright for this article is retained by the author(s), with first publication rights granted to the journal.

This is an open-access article distributed under the terms and conditions of the Creative Commons Attribution license which permits unrestricted use, distribution, and reproduction in any medium, provided the original work is properly cited. 